\title{
Rendimento de feijão-vagem em função de doses de $\mathrm{K}_{2} \mathrm{O}$
}

Ademar Pereira de Oliveira'; Jandiê Araújo Silva²; Adriana Ursulina Alves²; Carina Seixas M Dorneles²; Anarlete Ursulino Alves ${ }^{3}$; Arnaldo Nonato P. de Oliveira ${ }^{3}$; Edson A. Cardoso ${ }^{3}$; Iordam da Silva Cruz ${ }^{4}$

${ }^{1}$ UFPB, CCA, C. Postal 02, 58397-000 Areia-PB; Bolsista em produtividade em pesquisa CNPq; ${ }^{2}$ Pós-graduando; ${ }^{3} \mathrm{Graduando} ;{ }^{4} \mathrm{Bolsista}$ Apoio Técnico CNPq; E-mail: ademar@cca.ufpb.br.

\section{RESUMO}

Avaliou-se o efeito de doses crescentes de $\mathrm{K}_{2} \mathrm{O}$ sobre o rendimento de vagens do feijão-vagem em um experimento na UFPB, em Areia (PB), em um NEOSSOLO REGOLÍTICO Psamítico Típico. O delineamento experimental empregado foi de blocos casualizados, com seis tratamentos $(0 ; 50 ; 100 ; 150 ; 200$ e $250 \mathrm{~kg}$ $\mathrm{ha}^{-1}$ de $\mathrm{K}_{2} \mathrm{O}$ ), em quatro repetições. Cada parcela continha 60 plantas espaçadas em 1,0 m x 0,2 m. O número máximo de vagens por planta (20 vagens) e a máxima produção por planta $(171 \mathrm{~g})$ foram obtidos, respectivamente, com 145 e $173 \mathrm{~kg} \mathrm{ha}^{-1}$ de $\mathrm{K}_{2} \mathrm{O}$, e a produtividade de vagens, atingiu valor máximo estimado de $25,3 \mathrm{t} \mathrm{ha}^{-1}$ na dose de $171 \mathrm{~kg} \mathrm{ha}^{-1}$ de $\mathrm{K}_{2} \mathrm{O}$. A dose mais econômica de $\mathrm{K}_{2} \mathrm{O}$ para a produtividade de vagens foi de $165 \mathrm{~kg} \mathrm{ha}^{-1}$. A dose econômica representou $96 \%$ daquela responsável pela máxima produtividade de vagens. As doses de $\mathrm{K}_{2} \mathrm{O}$ com as quais obtiveram-se a máxima produtividade de vagens e máximo retorno econômico, se correlacionaram, respectivamente, com 181 e $176 \mathrm{mg} \mathrm{dm}^{-3}$ de $\mathrm{K}$ disponível pelo extrator de Mehlich1.

Palavras-chave: Phaseolus vulgris L, nutrição mineral, produção, retorno econômico, adubação potássica.

\begin{abstract}
Snap bean yield in function of $\mathrm{K}_{2} \mathrm{O}$ levels

Aiming to evaluate the effect of $\mathrm{K}_{2} \mathrm{O}$ levels on the increase of snap bean yield, an experiment was performed in Paraíba State, Brazil, in a Quartz Psamment soil. The experimental design was of randomized blocks, with six treatments $(0 ; 50 ; 100 ; 150 ; 200$ and $250 \mathrm{~kg} \mathrm{ha}^{-1}$ of $\mathrm{K}_{2} \mathrm{O}$ ), in four replications. Each plot contained 40 plants spaced $1.0 \mathrm{~m}$ x $0.2 \mathrm{~m}$. Pods maximum number/plant (20 pods) and the maximum yield/plant (171 g), were obtained, respectively with 145 and $173 \mathrm{~kg} \mathrm{ha}^{-1}$ of $\mathrm{K}_{2} \mathrm{O}$, and pods yield reached maximum value around $25,3 \mathrm{tha}^{-1}$ at the level of $171 \mathrm{~kg} \mathrm{ha}^{-1}$ of $\mathrm{K}_{2} \mathrm{O}$. The most economic level of $\mathrm{K}_{2} \mathrm{O}$ for the production of pods was of $165 \mathrm{~kg} \mathrm{ha}$ ${ }^{1}$. The most economic level represented $96 \%$ comparing to that responsible for maximum pods production. The $\mathrm{K}_{2} \mathrm{O}$ levels that obtained maximum pods production and economic return were correlated, respectively, with 181 and $176 \mathrm{mg} \mathrm{dm}^{-3}$ of $\mathrm{K}$ available for the extractor Mehlich 1.
\end{abstract}

Keywords: Phaseolus vulgaris L, mineral fertilization, yield, economic return, potassium fertilization.

\section{(Recebido para publicação em 19 de dezembro de 2005; aceito em 26 de fevereiro de 2007)}

$\mathrm{O}$ feijão-vagem destaca-se entre as hortaliças mais populares, ocupando a décima terceira posição em termos de importância econômica e sexta em volume produzido. No Nordeste, temse destacado como uma das mais importantes hortaliças cultivadas (Ramalho, 2003). Na Paraíba, seu consumo e produção vêm aumentando significativamente, com preferência por cultivares de crescimento indeterminado, pelo fato de apresentarem maior produtividade (Peixoto et al., 1993). Sua exploração comercial visa o aproveitamento das vagens ainda tenras, para consumo humano, podendo ser também industrializadas, sendo ricas em vitaminas e sais minerais (Filgueira, 2000).

O potássio é exigido pelas plantas em grande quantidade e sua função está relacionada especialmente com as enzimas que operam em quase todas as reações da planta. No período da frutificação sua presença em abundância é importante, pois ele auxilia o en- chimento e o crescimento de grãos e frutos. Por outro lado, a sua deficiência é caracterizada pelo crescimento lento, plantas com raízes pouco desenvolvidas, caules fracos e muito flexíveis, plantas mais suscetíveis a ataques de doenças, e ainda, à formação de sementes e frutos pouco desenvolvidos (Pittella, 2003).

A disponibilidade do potássio no solo ocupa uma posição intermediária entre o $\mathrm{N}$ e o $\mathrm{P}$, isto é, não sofre lixiviação tão intensa quanto o primeiro e nem é fixado tão fortemente quanto o segundo; o risco de lixiviação do K é maior nos solos arenosos, influenciando seus teores críticos no solo e na planta (Lana et al., 2002). De maneira geral, os locais de maior concentração desse nutriente no solo coincidem com os locais de maior umidade, evidenciando seu caminhamento por fluxo de massa. Isto significa que a distribuição de potássio no solo correlaciona-se com a distribuição de água no solo, indicando que se pode ter elevado controle de sua lo- calização no solo em função da disponibilidade de água, controlando consequentemente sua lixiviação (Zanini, 1991). O fornecimento de potássio de forma localizada aumenta a probabilidade de perdas por lixiviação e eleva seu efeito salino, pela alta concentração em área restrita.

Nos solos arenosos, ocorre menor perda desse nutriente por lixiviação. Além disso, em solos com o nível de pH adequado a perda do potássio pode ser reduzida pela quantidade balanceada de Ca e Mg (Raij, 1991). Modificações nos teores de $\mathrm{Ca}$ e $\mathrm{Mg}$ no solo, afetam a absorção de potássio pelas plantas devido à competição pelos mesmos sítios de absorção, fenômeno conhecido como antagonismo Ca-Mg (Silva, 1980).

As hortaliças são exigentes em potássio disponível no solo, sendo esse o primeiro macronutriente em ordem de extração na maioria delas, por favorecer a formação e transladação de carboidratos e o uso eficiente da água 
pela planta; por facilitar a absorção e utilização de outros nutrientes como o cálcio e melhorar a qualidade do produto e o valor de mercado. No entanto, o excesso de potássio pode dificultar a absorção de cálcio e magnésio (Filgueira, 2000). Alguns autores relataram efeitos positivos do potássio sobre diversas hortaliças, como por exemplo, melancia (Sundstrom \& Carter, 1983), meloeiro (Nerson et al., 1997), tomateiro, (Fontes et al., 2000) e cenoura e cebola (Shibairo et al., 1998). No feijão-comum, a deficiência de potássio retarda a maturação, proporciona perda no vigor da semente e redução no desenvolvimento dos grãos (Oliveira et al., 1996).

Embora o feijão-vagem possa absorver, em condições favoráveis, quantidades significativas de potássio (Rosolem,1996), pouco se conhece a respeito das quantidades a utilizar visando a obtenção de rendimentos satisfatórios. As poucas informações disponíveis na literatura em nível nacional sobre a nutrição mineral do feijãovagem indicam o fósforo e o cálcio, como os nutrientes que possibilitam respostas mais acentuadas em sua produtividade (Blanco et al., 1997; Filguera, 2000), mas recomendam, respectivamente, para solos de baixa a média fertilidade o emprego de 100 a 150 e de 60 a $90 \mathrm{~kg} \mathrm{ha}^{-1}$ de $\mathrm{K}_{2} \mathrm{O}$, aplicados 8 a 10 dias antes da semeadura. Para as condições regionais, em solo com característica arenosa, Araújo et al. (2001) obtiveram produtividade de $39,6 \mathrm{t} \mathrm{ha}^{-1}$ de vagens com o fornecimento de $40 \mathrm{t} \mathrm{ha}^{-1}$ de esterco de suíno acrescido de $450 \mathrm{~kg}$ de superfosfato simples, $170 \mathrm{~kg}$ de cloreto de potássio e $300 \mathrm{~kg} \mathrm{ha}^{-1}$ de sulfato de amônio. Oliveira et al. (2003), avaliando doses crescentes de $\mathrm{N}$ observaram que o emprego de 54 e $55 \mathrm{~kg}$ $\mathrm{ha}^{-1}$ de N, aplicadas no solo e na folha, respectivamente, resultaram em produtividades de 29 e $28 \mathrm{t} \mathrm{ha}^{-1}$ de vagens e Oliveira et al. (2005) estudando doses de $\mathrm{P}_{2} \mathrm{O}_{5}$ verificaram que a máxima produtividade de vagens $\left(30,1 \mathrm{tha}^{-1}\right)$ foi obtida na dose estimada de $252 \mathrm{~kg} \mathrm{ha}^{-1}$.

O objetivo deste trabalho foi avaliar o rendimento do feijão-vagem cultivado com doses crescentes de $\mathrm{K}_{2} \mathrm{O}$, em NEOSSOLO REGOLÍTICO Psamítico, representativo das áreas cultivadas na região de Areia (PB).

\section{MATERIAL E MÉTODOS}

O trabalho foi conduzido na UFPB, em Areia (PB), em NEOSSOLO REGOLÍTICO Psamítico Típico textura franca (Embrapa, 1999), entre julho e outubro de 2004, com predominância de alta precipitação e temperatura amena. A temperatura média do ar $\left(\mathrm{em}^{\circ} \mathrm{C}\right)$, a precipitação pluviométrica (em $\mathrm{mm}$ ) e a umidade relativa (em \%) do período de execução do experimento foram, respectivamente: julho $=21,3 ; 90,7 ; 85$; agosto $=21,2 ; 233 ; 89$; setembro $=22,4 ; 85,7$; 80 e outubro $=23,4 ; 102 ; 73$. A caracterização química e granulométrica da camada de 0-20 cm, realizada segundo Embrapa (1997), resultou em: $\mathrm{pH}\left(\mathrm{H}_{2} \mathrm{O}\right)$ $=5,7 ; \mathrm{P}=33,7 \mathrm{mg} \mathrm{dm}^{-3} ; \mathrm{K}=53,8 \mathrm{mg} \mathrm{dm}^{-3}$; $\mathrm{H}+\mathrm{Al}=1,79=\mathrm{cmol}_{\mathrm{c}} \mathrm{dm}^{-3} ; \mathrm{Al}^{+3}=0,00$ $\mathrm{cmol}_{\mathrm{c}} \mathrm{dm}^{-3} ; \mathrm{Ca}^{+2}=2,45 \mathrm{cmol}_{\mathrm{c}} \mathrm{dm}^{-3} ; \mathrm{Mg}^{+2}$ $=0,70 \mathrm{cmol}_{c} \mathrm{dm}^{-3} ; \mathrm{CTC}=3,29 \mathrm{cmol}_{\mathrm{c}} \mathrm{dm}^{-3}$ e matéria orgânica $=15,8 \mathrm{~g} \mathrm{dm}^{-3}$; areia grossa $=672 \mathrm{~g} \mathrm{~kg}^{-1}$; areia fina $=125 \mathrm{~g} \mathrm{~kg}^{-1}$; silte $=126 \mathrm{~g} \mathrm{~kg}^{-1}$; argila $=77 \mathrm{~g} \mathrm{~kg}^{-1}$; densidade do solo $=1,28 \mathrm{~g} \mathrm{~cm}^{-3}$.

Adotou-se o delineamento experimental de blocos casualizados com seis doses de $\mathrm{K}_{2} \mathrm{O}(0 ; 50 ; 100 ; 150 ; 200$ e $\left.250 \mathrm{~kg} \mathrm{ha}^{-1}\right)$, na forma de cloreto de potássio, em quatro repetições. A parcela foi composta por 60 plantas, dispostas em três fileiras com 20 plantas cada, espaçadas de 1,0 m entre linhas e de 0,2 $\mathrm{m}$ entre plantas. A adubação de plantio constou do fornecimento de $20 \mathrm{t} \mathrm{ha}^{-1} \mathrm{de}$ esterco bovino curtido, $500 \mathrm{~kg} \mathrm{ha}^{-1}$ superfosfato simples, além das doses de $\mathrm{K}_{2} \mathrm{O}$ definidas como tratamentos, aplicadas de forma localizada. Na adubação em cobertura foram fornecidos 140 $\mathrm{kg} \mathrm{ha}^{-1}$ de uréia, parcelados $50 \%$ aos 20 dias e $50 \%$ aos 40 dias após a semeadura. Foram semeadas quatro sementes por cova da cv. Macarrão Trepador Hortivale, efetuando-se, após 15 dias, o desbaste para duas plantas por cova e a prática de tutoramento. Realizaram-se os tratos culturais recomendados para a cultura, incluindo irrigação por aspersão, nos períodos de ausência de chuvas; capinas com enxadas, mantendose a área livre de plantas invasoras e pulverizações com Deltamethrina 2,5 E
(20 ml/20 L de $\mathrm{H}_{2} \mathrm{O}$ ), para controlar cigarrinha verde (Empoasca braemer).

Nas cinco colheitas foram obtidos o número e produção de vagens por planta e a produtividade de vagens. Ao final da colheita efetuou-se a amostragem do solo (0-20 $\mathrm{cm}$ de profundidade), coletando-se dez amostras simples ao acaso por parcela, as quais originaram uma amostra composta para se determinar as concentrações de $\mathrm{K}$ disponível pelo extrator Mehlich 1, em função das doses de $\mathrm{K}_{2} \mathrm{O}$.

Os resultados obtidos foram submetidos às análises de variância e de regressão, utilizando-se o "software" SAEG (2000), sendo selecionado para expressar o comportamento das doses de $\mathrm{K}_{2} \mathrm{O}$ sobre as características avaliadas, o modelo significativo que apresentou maior coeficiente de determinação. Nas significâncias das análises de variância e de regressão foi considerado o nível de probabilidade de $5 \%$ pelo teste F. O teste " $t$ " foi utilizado para testar os coeficientes da regressão no mesmo nível de probabilidade.

A dose de máxima eficiência econômica de $\mathrm{K}_{2} \mathrm{O}$ foi calculada igualando-se a derivada primeira da equação de regressão à relação entre preços do insumo $\left(\mathrm{R} \$ / \mathrm{kg}\right.$ de $\left.\mathrm{K}_{2} \mathrm{O}\right)$ e do produto (R $\$ / k g$ de vagens) (Raij, 1991; Natale et al., 1996). Os preços adotados foram aqueles vigentes em Areia-PB em dezembro de 2004: $\mathrm{R} \$ 2,50 / \mathrm{kg}$ de $\mathrm{K}_{2} \mathrm{O}$ e $\mathrm{R} \$ 0,50 / \mathrm{kg}$ de vagens, ressaltando-se, porém, que o preço do quilograma de vagens correspondeu ao utilizado pelo produtor, podendo variar a cada ano conforme demanda e oferta. No entanto, a fim de atenuar os problemas de variação cambial, trabalhou-se com uma relação de troca ao invés de moeda corrente (Natale et al., 1996), procurandose assim dados mais estáveis. Portanto, a "moeda" utilizada nos cálculos, foi o próprio fruto, considerando-se a seguinte relação de equivalência: quilograma de $\mathrm{K}_{2} \mathrm{O} / \mathrm{kg}$ de frutos igual a 5 , sendo a dose mais econômica calculada por meio da relação de dy/dx $=a_{1}+2 a_{2} x$. A doses mais econômica ( $x$ ') foi então calculada por:

$$
\begin{aligned}
& x^{\prime}=a_{1}-\text { relação de equivalência } \\
& 2\left(-a_{2}\right)
\end{aligned}
$$


Onde $\mathbf{x}$ ' representa a dose econômica, $\mathbf{a}_{1}$ a taxa de incremento de produção e $\mathbf{a}_{2}$, o ponto de máxima produção.

\section{RESULTADOS E DISCUSSÃO}

Estabeleceram-se relações quadráticas crescentes entre as doses de $\mathrm{K}_{2} \mathrm{O}$ e o número e a produção de vagens por planta e a produtividade de vagens. As doses de $\mathrm{K}_{2} \mathrm{O}$ que proporcionaram o número máximo de vagens por planta (20 vagens) e a produção máxima de vagens por planta $(171 \mathrm{~g})$, foram 145 e $173 \mathrm{~kg}$ $\mathrm{ha}^{-1}$ de $\mathrm{K}_{2} \mathrm{O} \mathrm{kg} \mathrm{ha}{ }^{-1}$, respectivamente, verificando-se decréscimos a partir dessas doses (Figuras 1 e 2). Araújo et al. (2001), na região de Areia (PB) com a mesma cultivar empregada no presente estudo, obteve número médio de 29 vagens/planta e produção de vagens/planta de $299 \mathrm{~g}$ com a adição de $100 \mathrm{~kg} \mathrm{ha}^{-1} \mathrm{de}$ $\mathrm{K}_{2} \mathrm{O}$ em solo com $153 \mathrm{mg} \mathrm{dm}^{-3}$ de potássio residual. Provavelmente as médias mais elevadas obtidas por esses autores foram ocasionadas pelas baixas precipitações registradas no período da condução do experimento, média de $15 \mathrm{~mm}$ mensal, o que possivelmente reduziu a lixiviação do potássio, e pelo fornecimento de $40 \mathrm{t} \mathrm{ha}^{-1}$ de esterco suíno, o que possivelmente melhorou as características físicas do solo, auxiliando na melhor absorção dos nutrientes.

A produtividade de vagens atingiu valor máximo estimado de $25,3 \mathrm{t} \mathrm{ha}^{-1}$ na dose de $171 \mathrm{~kg} \mathrm{ha}^{-1}$ de $\mathrm{K}_{2} \mathrm{O}$ (Figura 3). Esta produtividade demonstrou que o potássio desempenha importante papel na produção de vagens no feijão-vagem, já que ficou acima da média nacional definida por Tessariolli Neto \& Groppo (1992) em 25,0 t ha-1 para cultivares de feijão-vagem com hábito de crescimento indeterminado. Tal resultado pode ter ocorrido em função de um maior estímulo ao desenvolvimento do sistema radicular, formação dos primórdios das partes reprodutivas e dos frutos (Filgueira, 2000), proporcionado pela dose de $\mathrm{K}_{2} \mathrm{O}$ responsável pela produtividade máxima, conferindo ao feijãovagem condições nutricionais para expressar seu potencial máximo produtivo de vagens.

O fornecimento de doses adequadas de potássio assegura às hortaliças a pos-

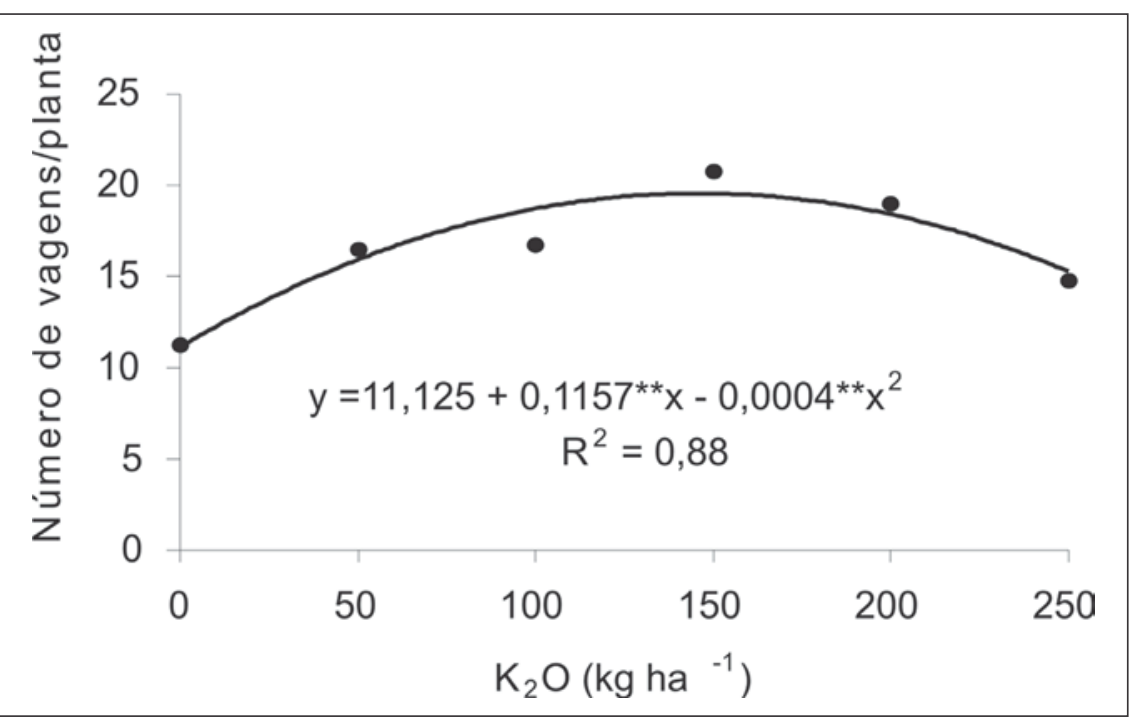

Figura 1. Número de vagens por planta no feijão-vagem, em função de doses de $\mathrm{K}_{2} \mathrm{O}$ (Number of pods per plant, as result of doses of $\mathrm{K}_{2} \mathrm{O}$ ). Areia, UFPB, 2005.

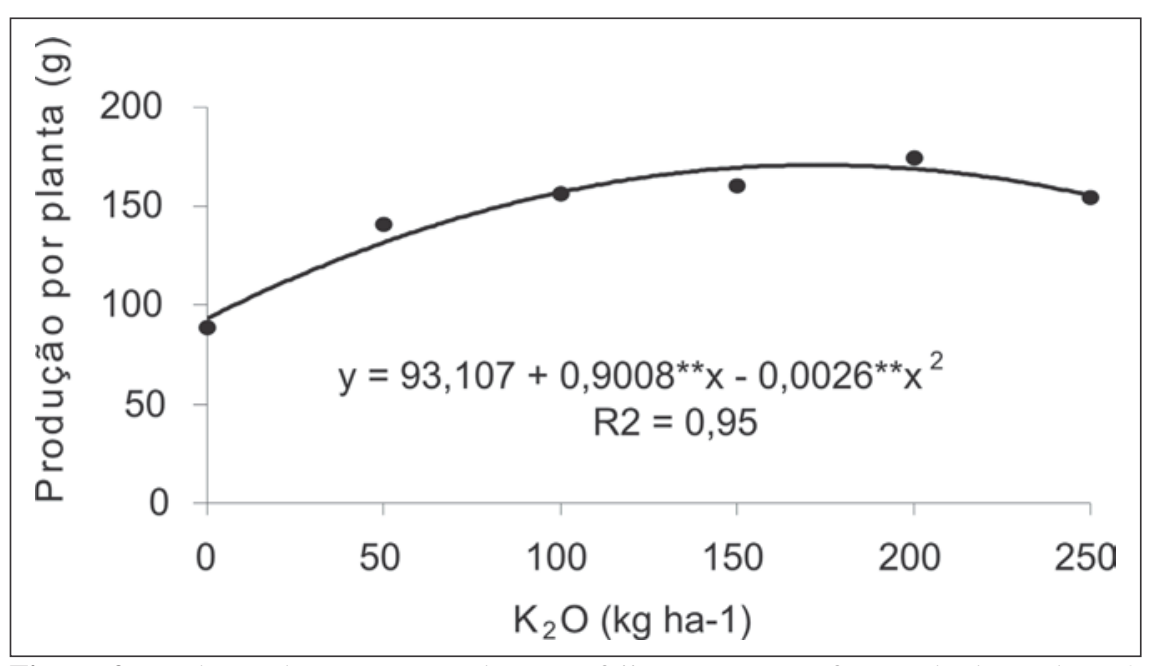

Figura 2. Produção de vagens por planta no feijão-vagem, em função de doses de $\mathrm{K}_{2} \mathrm{O}$ (Yield of pods per plant, as result of doses of $\mathrm{K}_{2} \mathrm{O}$ ). Areia, UFPB, 2005.

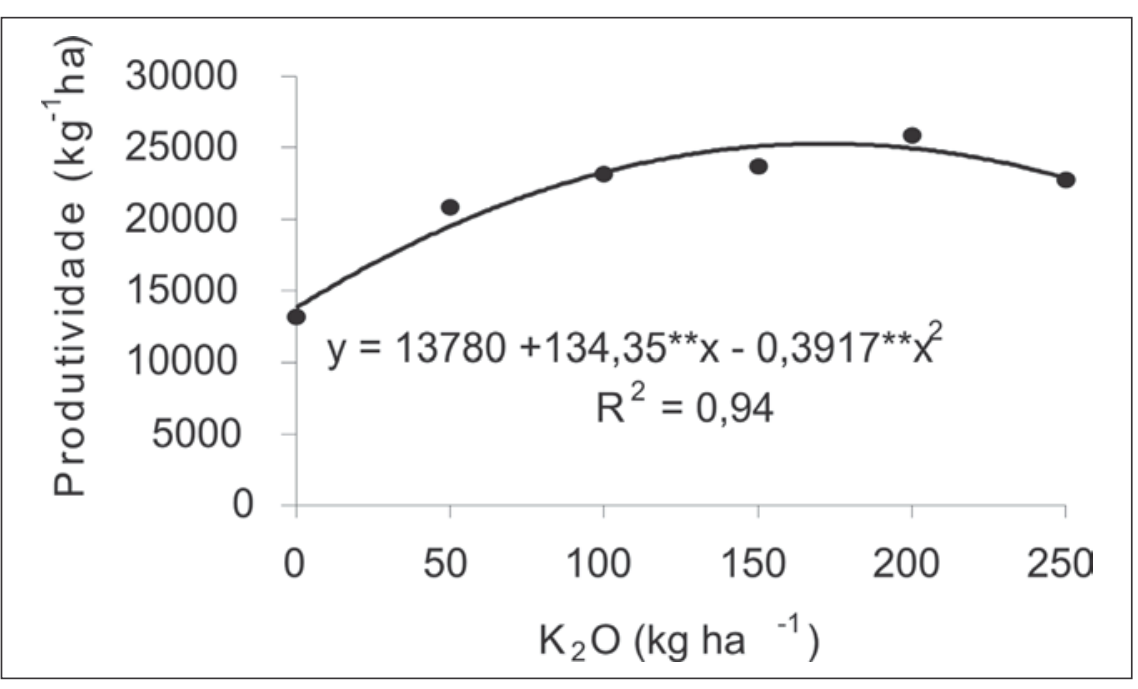

Figura 3. Produção de vagens no feijão-vagem, em função de doses de $\mathrm{K}_{2} \mathrm{O}$ (Yield of pods as result of doses of $\mathrm{K}_{2} \mathrm{O}$ ). Areia, UFPB, 2005. 


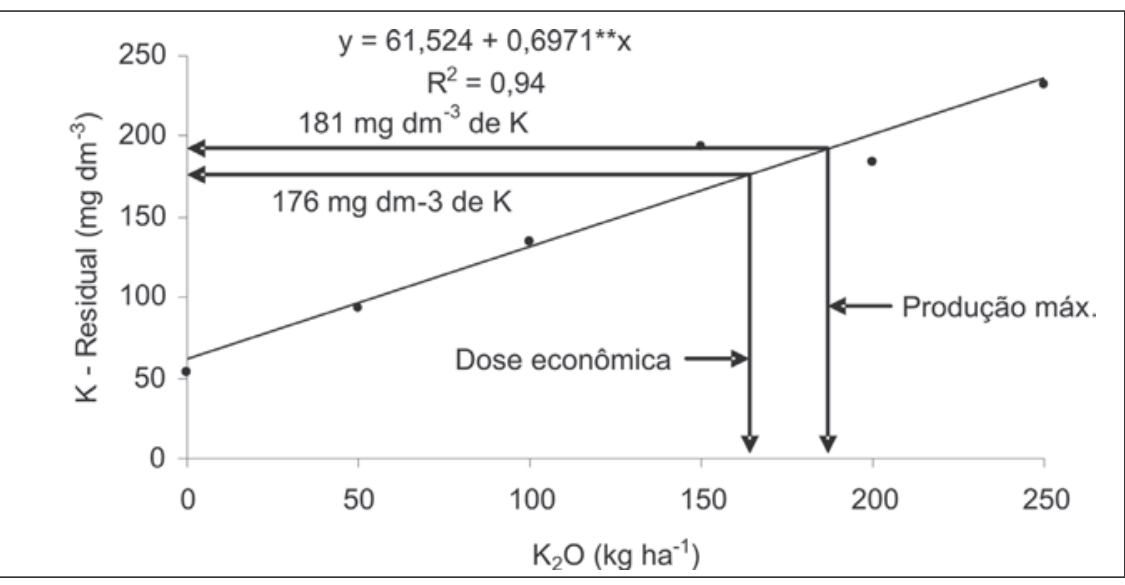

Figura 4. Relação entre teor de $\mathrm{K}$-disponível no solo (Mehlich), e as doses de $\mathrm{K}_{2} \mathrm{O}$ aplicadas antes do plantio. Os valores entre parênteses indicam doses de $\mathrm{K}_{2} \mathrm{O}$ e o teor de $\mathrm{K}$ disponível no solo que corresponde à máxima produção de vagens e o máximo retorno econômico (Relation between the disponible $\mathrm{K}$ in soil (Mehlich) and doses of $\mathrm{K}_{2} \mathrm{O}$ applied before planting date. Values in parentheses indicate doses of $\mathrm{K}_{2} \mathrm{O}$ and content of disponible $\mathrm{K}$ in the soil corresponding the maximum yield of pods and the maximum economic return). Areia, UFPB, 2005

sibilidade de desenvolver, plenamente, o seu potencial produtivo, incrementado pela aplicação de outros nutrientes (Filgueira, 2000). Portanto, é provável que durante o crescimento e desenvolvimento das plantas, a dose de $\mathrm{K}_{2} \mathrm{O}$ responsável pela máxima produção, juntamente com os nutrientes adicionados ao solo, tenham suprido as necessidades nutricionais do feijão-vagem. Em feijãovagem, elevações nas produções de vagens comerciais foram observadas por Ishimura et al. (1983) e Peixoto et al. (2002), com o fornecimento de doses adequadas de NPK.

A redução da produtividade de vagens em doses acima de $171 \mathrm{~kg} \mathrm{ha}^{-1} \mathrm{de}$ $\mathrm{K}_{2} \mathrm{O}$, indica que o excesso deste elemento foi prejudicial ao desenvolvimento do feijão-vagem, possivelmente em conseqüência da redução da absorção de Ca e Mg (Carnicelli et al., 2000) e prejuízo no desenvolvimento do sistema radicular e da parte aérea da planta ocasionado pelo elevado índice salino do potássio (Grangeiro \& Cecílio Filho, 2004), influenciando de forma negativa o desenvolvimento fisiológico das plantas e a produção de vagens.

A dose mais econômica de $\mathrm{K}_{2} \mathrm{O}$ foi de $165 \mathrm{~kg} \mathrm{ha}^{-1}$, com produção de $25,3 \mathrm{t}$ $\mathrm{ha}^{-1}$ de vagens. Esse resultado representa um incremento de $11,5 \mathrm{t} \mathrm{ha}^{-1}$ de vagens, em relação à ausência de $\mathrm{K}_{2} \mathrm{O}$. A quantidade de vagens necessária para a aquisi- ção de $165 \mathrm{~kg} \mathrm{ha}^{-1}$ foi de $616 \mathrm{~kg} \mathrm{ha}^{-1}$ que, deduzida do incremento calculado, resultou em superávit de 10,9 $\mathrm{t} \mathrm{ha}^{-1}$.

A dose econômica representou mais de $96 \%$ daquela responsável pela produtividade máxima, o que pode indicar a viabilidade do emprego de potássio no cultivo de feijão-vagem.

A dose de $\mathrm{k}_{2} \mathrm{O}$ responsável pela máxima produção de vagens se correlacionou com $181 \mathrm{mg} \mathrm{dm}^{-3}$ de $\mathrm{K}$ disponível pelo extrator Mehlich 1; enquanto que para o máximo retorno econômico, esta foi de $176 \mathrm{mg} \mathrm{dm}^{-3}$ (Figura 4). Isto indica que para a produção de vagens, a probabilidade de ocorrência de resposta do feijão-vagem ao emprego do potássio, em solos semelhantes ao do presente estudo, será minimizada quando o teor de K-disponível for superior a $176 \mathrm{mg} \mathrm{dm}^{-3}$. Os altos valores residuais verificados para o $\mathrm{K}_{2} \mathrm{O}$ podem ser explicados pela baixa mobilidade do potássio no solo (Grangeiro \& Cecílio Filho, 2004) e pela menor adsorção do K em solos arenosos (Raij, 1991).

Nas condições regionais de Areia, para o estabelecimento do feijão-vagem em Neossolo Regolítico Psamítico Típico, textura franca, com características químicas semelhantes às desta pesquisa, deve ser recomendada a aplicação de $165 \mathrm{~kg} \mathrm{ha}^{-1}$ de $\mathrm{K}_{2} \mathrm{O}$. Esta dose extrapola em muito a recomendação de 60 a $90 \mathrm{~kg} \mathrm{ha}^{-1}$ de $\mathrm{K}_{2} \mathrm{O}$, para essa hortaliça, conforme Filgueira (2000), e se aproxima da recomendação de 150 $\mathrm{kg} \mathrm{ha}^{-1}$ de acordo Blanco et al. (1997)

\section{REFERÊNCIAS}

ARAÚJO JS; OLIVEIRA AP; SILVA JAL; RAMALHO CI; COSTA NETO FL. 2001. Rendimento do feijão-vagem cultivado com esterco suíno e adubação mineral. Revista Ceres 48: 501-510.

BLANCO MCSG; GROPPO GA; TESSARIOLI NETO J. 1997. Feijão vagem (Phaseolus vulgaris L.). Manual Técnico de Culturas, Campinas-SP, n. 8, p. 63-65.

CARNICELLI JH; PEREIRA PRG; FONTES PCR; CAMARGO MI. 2000. Índices de nitrogênio na planta relacionados com a produção comercial de cenoura. Horticultura Brasileira 18: 808-810, n.8. Suplemento.

Embrapa. Centro Nacional de Pesquisa do Solo. 1999. Sistema Brasileiro de Classificação de Solos. Brasília. 412 p.

Embrapa. Serviço Nacional de Levantamento e Conservação do Solo. 1997. Manual de métodos de análise de solo. Rio de Janeiro: Ministério da Agricultura. $212 \mathrm{p}$.

FILGUEIRA, FAR. 2000. Novo manual de olericultura: agrotecnologia moderna na produção e comercialização de hortaliças. Viçosa: UFV. 402 p.

FONTES PCR; SAMPAIO R; FINGER FL. 2000a. Fruit size, mineral composition and quality of trickler-irrigated tomatoes as affected by potassium rates. Pesquisa Agropecuária Brasileira 35: 21-25.

GRANGEIRO LC; CECÍLIO FILHO AB. 2004. Exportação de nutrientes pelos frutos de melancia em função de épocas de cultivo, fontes e doses de potássio. Horticultura Brasileira 22: 740-743.

ISHIMURA I; FEITOSA CT; LISBAO RS; PASSOS FA; FORNASIER JB; NODA M. 1983. Diferentes doses de N, P, K na produção de feijão-vagem (Phaseolus vulgaris L.). In: CONGRESSO BRASILEIRO DE OLERICULTURA, 23. 1993. Rio de Janeiro. Resumos. Rio de Janeiro: SOB.

LANA RMQ; HAMAWAKF OT; LIMA LML; ZANÃO JÚNIOR LA. 2002. Resposta da soja a doses e modos de aplicação de potássio em solo de cerrado. Bioscience Journal 18: 1723.

NATALE W; COUTINHO ELM; BOARETTO A; PEREIRA FM. 1996. Dose mais econômica de adubo nitrogenado para a goiabeira em formação. Horticultura Brasileira 14: 196-199.

NERSON H; EDELSTEIN M; BERDUGO R; ANKORION Y. 1997. Monopotassium phosphate as a phosphorus and potassium source for greenhouse-winter-grown cucumber and muskmelon. Journal of Plant Nutrition 20 : 335-344.

OLIVEIRA IP; ARAUJO RS; DUTRA LG. 1996. Nutrição mineral e fixação biológica de nitrogênio. In: ARAÚJO RS; RAVAC; STONE LF; ZIMMERMANN MJO. 1996. Cultura do feijoeiro comum no Brasil. Piracicaba: Potafos, p.169-221. 
OLIVEIRA AP; TAVARES SOBRINHO J; SOUZA AP. 2003. Característica e rendimento do feijão-vagem em função de doses e formas de aplicação de nitrogênio. Ciência $e$ agrotecnologia 27: 714-720.

OLIVEIRA AP; CARDOSO MO; BARBOSA LJN; SILVA JEL; MORAIS MS. 2005. Resposta do feijão-vagem a $\mathrm{P}_{2} \mathrm{O}_{5}$ em solo arenoso com baixo teor de fósforo. Horticultura Brasileira 23: 128-132.

PEIXOTO N; BRAZ LT; BANZATO DA; MORAES EA; MOREIRA FM. 2002. Resposta de feijão-vagem a diferentes níveis de fertilidade. Horticultura Brasileira, Brasília 20: 593-596.

PEIXOTO N; SILVA LO; THUNG MDT; SANTOS G. 1993. Produção de sementes de linhagens e cultivares arbustivas de feijão-vagem em Anápolis. Horticultura Brasileira 11: 151152.
PITTELLA LC. 2006. Fertilização In: Bonsai Cube Morro Velho, setembro de 2003. Disponível em: http:// ww w.bonsaimorrovelho.com.br/ bcmv_mt_fertilizacao.html. Acesso em 21 de abril de 2006.

RAIJ BV. 1991. Fertilidade do solo e adubação. Piracicaba: Ceres potafos. 343 p

RAMALHO CI. 2003. Efeito da urina de vaca e adubação mineral sobre o rendimento e a salinidade do feijão-vagem (Phaseolus vulgaris L.). Areia: UFPB-CCA, 50 f. Dissertação (mestrado em Agronomia).

ROSOLEM C. 1996. Calagem e adubarão mineral. In ARAÚJO RS; RAVA C; STONE LF; ZIMMERMANN MJ. Cultura do feijoeiro comum no Brasil. Piracicaba: Potafos, p. 353390.

SAEG - Sistema para análise estatística, versão 8.0. 2000. Viçosa-MG Fundação Artur Bernardes.
SILVA JE. 1980. Balanço de cálcio e magnésio e desenvolvimento de milho em solos do cerrado. Pesquisa Agropecuária Brasileira 15: 329333.

SHIBAIRO S; UPADAHYAYA MK; TOIVONEN PMA. 1998. Potassium nutrition and postharvest moisture loss in carrots (Daucus carota L.). Journal of Horticultural Science \& Biotechnology 73: 862-866.

SUNDSTROM FJ; CARTER SJ. 1983. Influence of $\mathrm{K}$ and $\mathrm{Ca}$ on quality and yield of watermelon. Journal American Society for Horticultural Science 108: 879-881.

TESSARIOLI NETO J; GROPPO GA. 1992. A cultura do feijão-vagem. Boletim técnico. CATI. Campinas, n. 212, p.1-12.

ZANINI JR. 1991. Distribuição de água e do íon $\mathrm{K}^{+}$no solo, aplicados por fertirrigação em gotejamento. II - Teores de $\mathrm{K}^{+}$no bulbo molhado. ITEM - Irrigação e Tecnologia Moderna 46: 24-38. 